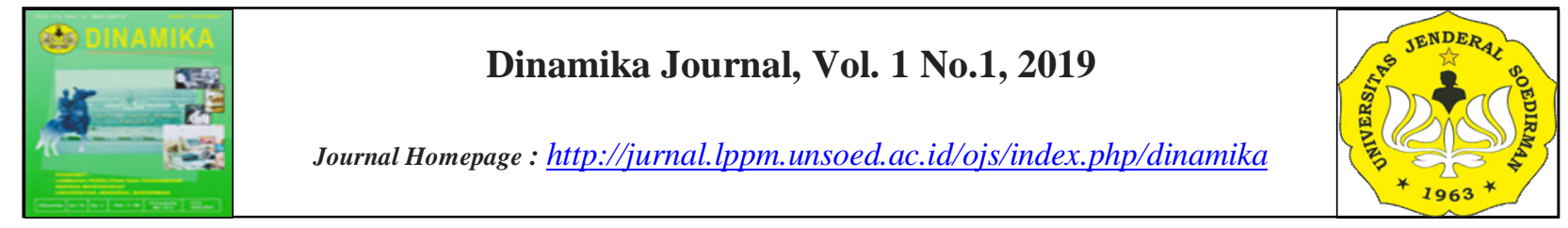

\title{
PEMBERDAYAAN KELOMPOK TANI MELALUI APLIKASI TEKNOLOGI REPRODUKSI PADA SAPI PASUNDAN DI KECAMATAN RANCAH KABUPATEN CIAMIS
}

\author{
Mas Yedi Sumaryadi ${ }^{1 *}$ dan Aras Prasetiyo Nugroho ${ }^{1}$ \\ ${ }^{1}$ Fakultas Peternakan, Universitas Jenderal Soedirman, Purwokerto \\ *Correspoding author: yedi.sumaryadi@yahoo.com
}

Received 20 May 2019; Accepted 4 July 2019; Available online 5 July 2019

\begin{abstract}
Abstrak
Pemberdayaan kelompok tani ternak sapi Pasundan melalui aplikasi teknologi reproduksi telah dilakukan di desa Situmandala, Rancah, Ciamis. Metode pendekatan dilakukan 2 (dua) tahap. Tahap pertama digunakan metode instruksional untuk memberikan informasi materi penyuluhan dan peragaan. Tahap kedua digunakan metode percontohan untuk mengaplikasikan paket teknologi reproduksi pada 18 ekor sapi Pasundan. Seluruh ternak sapi disinkronisasi berahi dengan disuntik $5 \mathrm{mg}$ i.m. prostaglandin per ekor sebanyak 2 (dua) kali dengan selang 11 hari, kemudian pada hari ke-9 setelah penyuntikan PGF2 $\alpha$ yang pertama, sapi percobaan dibagi kedalam 2 (dua) kelompok. Kelompok I sebanyak 12 ekor sapi diberi perlakuan Gonadotropin Releasing Hormone (GnRH) dosis 1,25-2,5 ml/bobot badan secara i.m. Kelompok II digunakan 6 ekor sapi diinjeksi NaCl Fisiologis 1,25-2,5 $\mathrm{ml} /$ bobot badan secara i.m. sebagai kontrol. Ternak sapi berahi diinseminasi buatan 2 kali dengan selang 6 jam. Peubah yang diamati meliputi persentase berahi dan kebuntingan secara palpasi rektal. Disimpulkan bahwa animo peternak dalam mengadopsi teknologi reproduksi sangat tinggi, terbukti $92 \%$ peternak telah mengetahui tanda-tanda berahi sapi Pasundan. Rataan persentase berahi sapi Pasundan yang diberi prostaglandin $F_{2} \alpha$ mencapai $62,5 \%$ dengan laju kebuntingan meningkat 147,49\% pada kelompok sapi yang diberi GnRH (83,33\%) dibandingkan kontrol $(33,67 \%)$.
\end{abstract}

Kata-kata kunci: Pemberdayaan, Dinamika Kelompok, Teknologi Reproduksi, sapi Pasundan 


\begin{abstract}
The empowerment of Pasundan cattle farmer groups through the application of reproductive technology has been carried out in the villages of Situmandala, Rancah, Ciamis. The approach method is carried out in 2 (two) stages. The first step is to use instructional methods to provide information on counseling and demonstration material. The second stage used a pilot method to apply the reproduction technology package to 18 Pasundan cattle. All cattle are synchronized with injections of $5 \mathrm{mg}$ i.m. prostaglandin per tail as much as 2 (two) times with an interval of 11 days, then on the 9th day after the first injection of PGF2 $\alpha$, the experimental cattle were divided into 2 (two) groups. Group I as many as 12 cows were treated with Gonadotropin Releasing Hormone (GnRH) dose of 1.25-2.5 ml / body weight i.m. Group II used 6 cows injected Physiological NaCl 1.25-2.5 ml / body weight i.m. as control. Estrous cattle are artificially inseminated 2 times at 6 hour intervals. The variables observed included the percentage of estrous and pregnancy by rectal palpation. It was concluded that the interest of farmers in adopting reproductive technology was very high, as evidenced by $92 \%$ of farmers having known estrous signs of Pasundan cattle. The average percentage of estrous for Pasundan cattle given prostaglandin F2 $\alpha$ reached $62.5 \%$ with the pregnancy rate increasing $147.49 \%$ in the group of cattle given GnRH (83.33\%) compared to controls $(33.67 \%)$.
\end{abstract}

Keywords: Empowerment, Group Dinamic, Reproduction Technology, Pasundan Cattle

\title{
1. PENDAHULUAN
}

Kondisi objektif yang terjadi pada sapi potong ternyata telah terjadi kesenjangan antara permintaan dan penyediaan daging, sehingga dibutuhkan pasokan daging impor atau impor sapi bakalan. Masalah yang dihadapi Indonesia sampai saat ini, bahwa peningkatan populasi ternak sapi potong sebagai penyangga produksi daging dirasakan sangat lambat, terutama karena laju pemotongan jauh melebihi laju reproduksi induk yang ada (Soehadji, 1995). Kondisi ini bila tidak dilakukan upaya untuk meningkatkan populasi dan produksinya, maka populasi sapi Pasundan sebagai plasma nutfah daerah akan terkuras karena tingginya angka pemotongan ternak (Dinas Provinsi Jawa Barat, 2015). Terlepas dari laju pemotongan yang meningkat, rendahnya keberhasilan reproduksi induk juga merupakan penghambat utama peningkatan populasi. Untuk mengatasi kondisi tersebut perlu upaya terobosan percepatan pemanfaatan teknologi melalui pendekatan kuantitatif (peningkatan populasi) dan pendekatan kualitatif (produktivitas per unit ternak).

Sapi Pasundan merupakan salah satu plasma nutfah yang perlu dilestarikan maupun dikembangkan di Jawa Barat dan telah ditetapkan sebagai rumpun ternak lokal Indonesia berdasarkan SK Menteri Pertanian Republik Indonesia Nomor 1051/Kpts/RI/SR.10/2014. Keberadaan plasma nutfah sapi tersebut merupakan modal dasar dalam pembentukan bibit ternak unggul dan perlu dilestarikan karena sejalan dengan amanah UU No. 18 Tahun 2009 (Utomo et al., 2015). Kegiatan pelestarian dan pengembangan sapi Pasundan melalui aplikasi teknologi reproduksi bertujuan untuk memberdayakan sapi lokal maupun peternak yang tergabung dalam wadah kelompok tani.

Aplikasi paket teknologi reproduksi melalui teknik manipulasi berahi, superovulasi, dan teknik inseminasi buatan (IB) diharapkan mampu meningkatkan populasi maupun produktivitas sapi Pasundan. Hal ini mengingat di lapangan umumnya sapi potong tidak menunjukkan siklus berahi yang normal sehingga perlu dimanfaatkan teknologi gertak berahi yang dipadukan dengan peningkatan kesuburan induk sapi, serta teknik IB sebagai teknologi 
persilangan dengan memanfaatkan keunggulan genetik pejantan. Dengan aplikasi paket teknologi tersebut tentunya akan memperbaiki kinerja reproduksi induk untuk menghasilkan anak sehingga jarak beranak menjadi lebih pendek. Hasil penelitian sebelumnya telah dilaporkan bahwa penyuntikan prostaglandin $\left(\mathrm{PGF}_{2} \alpha\right)$ secara eksogen sangat efektif untuk menggertak berahi pada sapi Perah (Pemanyun, 2009; Putro dan Kusumawati, 2014), sapi Potong (Kune dan Najamudin, 2002 ), terutama sapi potong Peranakan Ongole (Irmaylin dkk., 2012), sapi Aceh (Hafizuddin et al., 2012), sapi Bali (Handayani et al., 2012), sapi Gir (Ahlawat et al., 2015) bahkan memberi peluang terhadap keberhasilan kebuntingan pertama pada domba (Sumaryadi dan Manalu, 1996). Saat ini beberapa metode sinkronisasi berahi telah dikembangkan, antara lain dengan penggunaan sediaan progesterone, prostaglandin dan estrogen (Kune dan Najamudin, 2002; Mardiansyah et al., 2016; Ma'ruf et al., 2016). Tingkat berahi ternak tentunya akan memberikan petunjuk untuk ketepatan waktu IB (Walker et al., 2005; Kune dan Solihati, 2007).

Pemanfaatan teknologi manipulasi berahi yang diikuti pemberian gonadotrophin releasing hormone $(\mathrm{GnRH})$ ternyata di samping memicu tanda-tanda berahi juga dapat meningkatkan kesuburan induk sapi dengan merangsang tumbuh kembang folikel untuk berovulasi, serta meningkatkan jumlah korpus luteum dan massa plasenta (Sumaryadi dan Manalu, 1996; Afriani et al., 2014 ), sehingga dapat meningkatkan peluang terjadinya kebuntingan pada ternak (Mardiansyah et al., 2016). Hal ini sejalan dengan pendapat Sumaryadi et al. (2000) dan Sumaryadi (2004), bahwa modulasi hormon FSH-LH yang diinduksi GnRH mampu meningkatkan jumlah folikel yang berovulasi. Hal yang sama dilaporkan bahwa penyuntikan GnRH dapat menginduksi ovulasi dan kemudian menstimulasi peningkatan FSH endogen, yang diikuti terjadinya gelombang folikel pada sapi (Macmillan et al., 2003; Sato et al., 2005; Herbert dan Trigg, 2005; Putro dan Kusumawati, 2014).

Khalayak sasaran yang dijadikan protipe aplikasi teknologi reproduksi dilakukan pada para peternak yang tergabung dalam wadah kelompok tani ternak sapi Pasundan di Desa Situmandala, kecamatan Rancah, kabupaten Ciamis. Berdasarkan hal tersebut diharapkan kegiatan ini dapat memberdayakan dinamika kelompok tani dalam upaya melestarikan dan meningkatkan kinerja reproduksi sapi Pasundan sebagai plasma nutfah di Jawa Barat.

\section{METODE PELAKSANAAN}

Materi yang digunakan adalah 18 ekor ternak sapi Pasundan dengan kisaran bobot badan 100-150 kg milik peternak yang tergabung dalam wadah kelompok tani Desa Situmandala, kecamatan Rancah, kabupaten Ciamis.

Metode yang digunakan dalam kegiatan ini adalah metode intruksional melalui 2 (dua) tahap pelaksanaan, yaitu tahap pertama penyampaian informasi melalui penyuluhan dan peragaan, tahap kedua berupa aplikasi percontohan.

Tahap pertama, penyampaian informasi melalui kegiatan penyuluhan dan peragaan. Materi yang dikembangkan dalam penyuluhan adalah materi pokok berupa teknologi reproduksi yang meliputi teknik manipulasi berahi, teknik superovulasi, dan teknik inseminasi buatan (IB). Materi penunjang berupa kebijakan pemerintah daerah terhadap pengembangan sapi Pasundan, dan materi pemberdayaan dinamika kelompok tani. Tahap ini diikuti dengan peragaan bahan dan alat yang digunakan untuk aplikasi teknologi reproduksi.

Tahap kedua melakukan aplikasi percontohan teknologi reproduksi dengan menggunakan 18 ekor sapi Pasundan dengan kisaran bobot badan 100 - $150 \mathrm{~kg}$ milik peternak anggota kelompok tani. Seluruh ternak sapi percontohan diserentakan berahinya menggunakan hormon prostaglandin (PGF2 $\alpha$ ) dengan dosis $5 \mathrm{ml} / \mathrm{ekor}$ sebanyak 2 (dua) kali dengan selang waktu 11 hari, kemudian pada hari ke-9 setelah penyuntikan PGF2 $\alpha$ yang pertama, sapi percobaan dibagi kedalam 2 (dua) kelompok. Kelompok I sebanyak 12 ekor 
sapi diinjeksi Gonadotropin Releasing Hormone (GnRH) dosis 1,25 - 2,5 ml/bobot badan secara intramuskular. Kelompok II digunakan 6 ekor sapi diinjeksi $\mathrm{NaCl}$ Fisiologis 1,25 $2,5 \mathrm{ml} /$ bobot badan secara intramuskulair sebagai kontrol (GnRH $0 \mathrm{ml}$ ). Sapi yang berahi 2 4 hari setelah penyuntikan PGF2 $\alpha$ yang kedua dilakukan inseminasi buatan (IB) 2 kali dengan selang waktu 6 jam setelah IB pertama. Persentase berahi diamati dengan metode non return rate artinya sapi yang tidak menunjukkan berahi kemabli dalam satu siklus berahi dianggap bunting. Adapun laju kebuntingan diamati dengan metode palpasi rektal pada bulan ke-2 kebuntingan.

\section{HASIL DAN PEMBAHASAN}

Sebelum dilakukan kegiatan aplikasi paket teknologi reproduksi dalam upaya mengembangkan dinamika kelompok tani telah dilakukan pertemuan dengan seluruh anggota kelompok peternak sapi Pasundan. Hasil pertemuan disepakati bahwa pelaksanaan aplikasi paket teknologi reproduksi dalam upaya pemberdayaan kelompok tani dilakukan melalui 2 (dua) tahapan, antara lain sebagai berikut.

\section{Tahap I: Penyuluhan dan Peragaan}

Tahap pertama, penyampaian informasi melalui kegiatan penyuluhan dan peragaan ditujukan bagi para peternak. Pada tahap ini informasi yang diberikan berupa pengetahuan paket teknologi bioreproduksi yang terdiri dari teknik manipulasi berahi, teknik superovulasi, dan teknik inseminasi buatan (IB). Di samping untuk menambah wawasan diberikan informasi dari Dinas Peternakan setempat terkait pengembangan sapi Pasundan, dan materi untuk memberdayakan dinamika kelompok tani. Selanjutnya diikuti dengan peragaan bahan dan alat yang digunakan untuk aplikasi teknologi reproduksi.

Hasil penyuluhan dan peragaan menunjukkan bahwa perhatian dan partisipasi anggota kelompok tani cukup besar. Sebagai indikator keberhasilan penyampaian informasi melalui penyuluhan dan peragaan, ternyata 23 orang dari 25 peternak atau sekitar $92 \%$ telah mengetahui aktivitas reproduksi sapi Pasundan berupa tanda-tanda berahi organ reproduksi betina antara lain abang (merah), abuh (bengkak), anget (hangat), dan anyid (keluar lendir) yang dikenal dengan istilah $4 \mathrm{~A}$, di samping sebagian menunjukkan nafsu makan menurun dan gelisah sambil ngorong-ngorong (berteriak-teriak). Disamping para peternak menjadi tahu teknik superovulasi untuk menyuburkan induk sapi betina dengan pemberian obat hormon dan teknik perkawinan melalui inseminasi buatan yang mereka kenal dengan istilah kawin suntik. Hal ini sesuai dengan pendapat Marawali et al. (2001) dan Yusuf (2014) menyatakan bahwa ketika ternak betina mengalami berahi maka akan menampakkan beberapa gejala berahi yaitu menaiki sapi lainnya dan diam ketika dinaiki, vulva membengkak dan mengeluarkan lendir, serta nafsu makannya berkurang. Hal yang sama dilaporkan pula bahwa semakin jelas pengamatan visual tingkah laku dan kondisi vulva sapi yang berahi maka akan semakin akurat dan tepat pelaksanaan inseminasi buatan (Achyadi, 2009; Handarini et al., 2017). Kondisi ini tentunya akan semakin meningkatkan peluang terjadinya kebuntingan. Seperti yang dinyatakan sebelumnya, bahwa penentuan waktu berahi yang tepat pada sapi merupakan hal yang sangat penting untuk diketahui sebelum pelaksanaan IB (Walker et al., 2005; Kune dan Solihati, 2007; Abidin et al., 2012).

\section{Tahap II: Aplikasi Percontohan}

Hasil aplikasi teknologi reproduksi terhadap persentase berahi pada sapi Pasundan yang diberi perlakuan Gonadotropin releasing hormone $(\mathrm{GnRH})$ seperti tertera pada Tabel 1. 
Tabel 1. Persentase Berahi sapi Pasundan yang Diberi Perlakuan GnRH dan Kontrol

\begin{tabular}{lcc}
\hline \multicolumn{1}{c}{ Perlakuan } & Berahi & Tidak Berahi \\
\hline Diberi GnRH & 58,33 & 41,67 \\
Tanpa GnRH (Kontrol) & 66,67 & 33,33 \\
\hline
\end{tabular}

Hasil pada Tabel 1 menunjukkan bahwa persentase berahi sapi Pasundan yang diberi perlakuan $\mathrm{GnRH}$ tidak berbeda nyata $(\mathrm{P}<0,01)$ dibandingkan dengan kontrol. Persentase berahi sapi Pasundan yang diberi perlakuan GnRH dan kontrol masing-masing adalah 58,33 dan $66,67 \%$ atau rata-rata $62,5 \%$. Hal ini dapat dimengerti karena timbulnya berahi lebih ditentukan oleh pemberian hormon prostaglandin $\left(\mathrm{PGF}_{2} \alpha\right)$ eksogen yang sebelum perlakuan GnRH diberikan pada seluruh sapi percobaan. Hasil penelitian sebelumnya dilaporkan Sariubang dan Nurhayu (2011), bahwa penyuntikan hormon Capriglandin $\left(\mathrm{PGF}_{2} \alpha\right)$ sebanyak $3 \mathrm{~mL}$ dilakukan dua kali dengan selang 11 hari dari penyuntikan pertama memberikan respons sinkronisasi berahi induk sapi Bali. Prostaglandin $\left(\mathrm{PGF}_{2} \alpha\right)$ mempunyai sifat luteolotik, dapat menyebabkan hambatan secara drastis pengaliran darah yang menuju ke korpus luteum (CL) yang regresinya CL (Hafez, 2000).

Penentuan kebuntingan seekor ternak dapat dilakukan berdasarkan metode non return rate (NRR) dengan asumsi bahwa sapi yang telah di IB dan tidak berahi lagi, maka dianggap bunting. Hal ini sesuai dengan pendapat Susilawati (2011) bahwa NRR merupakan persentase jumlah ternak yang tidak kembali berahi antara hari 60-90 setelah dikawinkan, tetapi pengamatan NRR tidak dapat dijamin 100\% kebenarannya karena sekitar 5\% sapi yang bunting masih menunjukkan tanda-tanda berahi, sehingga untuk lebih akurat dilakukan pemeriksaan dengan cara palpasi rektal. Selanjutnya dinyatakan bahwa palpasi rektal merupakan metode pemeriksaan kebuntingan yang praktis, mudah dilaksanakan dan dapat diyakini kebenarannya.

Hasil aplikasi teknologi reproduksi terhadap persentase kebuntingan pada sapi Pasundan yang diberi perlakuan gonadotropin releasing hormone $(\mathrm{GnRH})$ seperti tertera pada Tabel 2.

Tabel 2. Persentase Kebuntingan Sapi Pasundan yang Diberi Perlakuan GnRH dan Kontrol

\begin{tabular}{lcc}
\hline \multicolumn{1}{c}{ Perlakuan } & Bunting & Tidak Bunting \\
\hline Diberi GnRH & $83,33 \%$ & $16,67 \%$ \\
Tanpa GnRH (Kontrol) & $33,67 \%$ & $66,67 \%$ \\
\hline
\end{tabular}

Hasil pada Tabel 2 menunjukkan bahwa persentase kebuntingan sapi Pasundan yang diberi perlakuan $\mathrm{GnRH}$ secara eksogen sangat nyata $(\mathrm{P}<0,01)$ lebih tinggi dibandingkan dengan kontrol. Laju kebuntingan sapi yang diberi perlakuan GnRH meningkat 147,49\% dibandingkan kontrol. Persentase kebuntingan pada sapi Pasundan yang diberi perlakuan GnRH dan kontrol masing-masing adalah 83,33 dan 33,67\%. Hal ini sesuai dengan pendapat Sonjaya (2012), bahwa GnRH merupakan hormon yang menstimulasi sekresi follicle stimulating hormone (FSH) dan luteinizing hormone ( $\mathrm{LH})$ dari hipofisis anterior yang berperan terhadap tumbuh kembang folikel dan proses ovulasi. Selanjutnya dinyatakan bahwa menjelang waktu ovulasi konsentrasi hormon estrogen cukup tinggi untuk menekan produksi FSH dan pelepasan LH sehingga terjadi ovulasi dengan menggertak pemecahan dinding folikel dan pelepasan ovum. Hal ini sejalan dengan pendapat Sumaryadi et al. (2000) dan Sumaryadi (2004), bahwa modulasi hormon FSH-LH yang diinduksi GnRH mampu meningkatkan jumlah folikel yang berovulasi. Hal yang sama dilaporkan bahwa penyuntikan GnRH dapat menginduksi ovulasi dan kemudian menstimulasi peningkatan FSH endogen, yang diikuti terjadinya gelombang folikel pada sapi dan terbukti dapat meningkatkan respon ovulasi (Kohram et al., 1998; Maidaswar, 2007). 
Semakin banyak folikel yang berovulasi maka semakin tinggi peluang terjadinya kebuntingan pada ternak. Hasil penelitian sebelumnya, bahwa peningkatan jumlah ovulasi meningkatkan keberhasilan kebuntingan pertama setelah berahi (Sumaryadi dan Manalu, 1996; Efendi et al., 2015; Mardiansyah et al., 2016).

\section{KESIMPULAN}

Secara keseluruhan disimpulkan kegiatan ini berjalan dengan baik, animo anggota kelompok tani untuk dapat mengadopsi pengetahuan tentang teknologi reproduksi sangat tinggi dan sangat responsif, dan $92 \%$ peternak telah mengetahui aktivitas reproduksi berupa tanda-tanda berahi baik tingkah laku maupun perubahan kondisi vulva sapi Pasundan. Rataan persentase berahi sapi Pasundan yang diberi prostaglandin $\mathrm{F}_{2} \alpha$ mencapai $62,5 \%$ dengan laju kebuntingan meningkat $147,49 \%$ pada kelompok sapi yang diberi GnRH $(83,33 \%)$ dibandingkan kontrol $(33,67 \%)$.

\section{UCAPAN TERIMA KASIH}

Ucapan terima kasih disampaikan kepada Tim Mahasiswa peneliti sapi Pasundan yang telah bekerjasama serta LPPM yang telah memberikan kesempatan dan biaya pelaksanaan kegiatan melalui dana BLU Universitas Jenderal Soedirman Tahun Anggaran 2018. Hal yang sama disampaikan kepada seluruh anggota Kelompok Tani Sapi Pasundan Desa Situmandala kecamatan Rancah Kabupaten dan Dinas Peternakan dan Perikanan kabupaten Ciamis atas kerjasamanya dalam pelaksanaan kegiatan ini.

\section{DAFTAR PUSTAKA}

Abidin, Z., Y.S. Ondho ., B. Sutiyono. 2012. Penampilan berahi sapi jawa berdasarkan poel 1, poel 2, dan poel 3. Animal Agriculture Journal 1(2), 86-92.

Afriani, T., Jaswandi, Defrinaldi., Y.E. Satria. 2014. Pengaruh Waktu Pemberian Gonadotropin Releasing Hormone $(\mathrm{GnRH})$ terhadap Jumlah Korpus Luteum dan Kecepatan Timbulnya Berahi pada Sapi Pesisir. Jurnal Peternakan Indonesia 16(3), 193-197.

Ahlawat, A.R., V. B. Dongre., S. N. Ghodasara, Murthy., P. U. Gajbhiye. 2015. "Single and Double Dose of PGF2a for Estrus Induction and Conception Rate in Gir Cows." Intas Polivet 16 (1), 54-56.

Achyadi, K.R. 2009. Deteksi Berahi pada Ternak Sapi. Pascasarjana Institut Pertanian Bogor.

Dinas Peternakan Propinsi Jawa Barat 2015. Laporan Populasi Sapi Potong di Propinsi Jawa Barat Tahun 2015. Bandung. Dinas Peternakan Provinsi Jawa Barat.

Efendi M, T. Siregar, Hamdan, Dasrul, C. Thasmi, Razali, A Sayuti., B Panjaitan. 2015. Angka kebuntingan sapi lokal setelah diinduksi dengan protokol ovsynch. Jurnal Medika Veteriner 9(2), 159 -162.

Hafez, E. S. E,. 2000. Reproduction In Farm Animals. $7^{\text {th }}$ edition. Lippincott Williams and Wilkins. Maryland. USA.

Hafizuddin, Jailani, Yusmadi., Suryani. 2012. Perbandingan Intensitas Berahi Sapi Aceh yang Disinkronisasi dengan Prostaglandin $\mathrm{F}_{2} \alpha$ dan Berahi Alami. Jurnal Kedokteran Hewan 6(2), 81-83. 
Handayani, U., F. Hartono., Siswanto. 2012. Respon Kecepatan Timbulnya Estrus dan Lama Estrus pada Berbagai Paritas Sapi Bali setelah Dua Kali Pemberian Prostaglandin F2 $\alpha$ (PGF2 $\alpha$ ). Jurnal Ilmiah Peternakan Terpadu 2(1), 33 - 40.

Herbert, C. A., T.E. Trigg. 2005.Applications of GnRH in control and management of fertility in female animals. J. Animal Reproductions Sci. 88(2), 141-153.

Irmaylin, S. M., M. Hartono., P. E. Santosa. 2012. "Respon Kecepatan Timbulnya Estrus dan Lama Estrus pada Berbagai Paritas Sapi Peranakan Ongole (PO) Setelah Dua Kali Injeksi Prostaglandin F2 $\alpha$ (PGF2 $\alpha$ ). Jurnal Kedokteran Hewan 2(1), 41- 49.

Kohram H, H. Twaqiramungu, D. Bousquet, J. Durocher., L.A. Gulibault. 1998. Ovarian Superstimulation after Follicular Wave Synchronization with GnRH at Two Different Stages of the Estrus Cycle in Cattle. Theriogenology 49, 1175-1186.

Kune, P., Najamudin. 2002. Respon estrus sapi potong akibat pemberian progesterone, prostaglandin F2 $\alpha$ dan estradiol benzoat dalam kegiatan sinkronisasi estrus. Jurnal Agroland. 9(4), 380-384.

Kune, P., N. Solihati. 2007. Tampilan Berahi dan Tingkat Kesuburan Sapi Bali Timor yang Diinseminasi. Jurnal Ilmu Ternak 7(1), 1-5.

Macmillan, K.L., B.V.E. Segwagwe., C.S. Pino. 2003. Associations between the manipulation of patterns of follicular development and fertility in cattle. Animal Reproduction Science 78, 327-344.

Maidaswar. 2007. Efisiensi Superovulasi pada Sapi melalui Sinkronisasi Gelombang Folikel dan Ovulasi. Tesis. Pascasarjana IPB. Bogor.

Marawali, A., M.T. Hine, Burhanuddin., H.L.L. Belli. 2001. Dasar-dasar ilmu reproduksi ternak. Departemen Pendidikan Nasional Direktorat Pendidikan Tinggi Badan Kerjasama Perguruan Tinggi Negeri Indonesia Timur. Jakarta.

Mardiansyah., E. Yuliani., S. Prasetyo. 2016. Respon Tingkah Laku Berahi, Service Per Conception, Non Return Rate, Conception Rate pada Sapi Bali Dara dan Induk yang Disinkronisasi Birahi dengan Hormon Progesteron. Jurnal Ilmu dan Teknologi Peternakan Indonesia 2(1), 134-143.

Ma'ruf, M. J., E. Kurnianto., Sutiyono. 2016. Perfoma Birahi Sapi PO pada berbagai BCS yang Disinkronsasi dengan Medroxy Progesteron Acetate di Satker Sumberejo Kendal. Jurnal Ilmu-Ilmu Peternakan 27(2), 35-43.

Pemanyun, T.G.O. 2009. Induksi Estrus dengan PMSG dan GnRH pada Sapi Perah Anestrus Postpartum. Buletin Veteriner 2(1), Philadelphia.

Putro, P., R. Wasito, H. Wuryastuty., S. Inrajulianto. 2008. Dinamika Perkembangan Folikel dan Profil Progesteron Plasma selama Siklus Estrus pada Sapi Perah. Animal Reproduction 10(2), 73-77.

Putro, P. P., A. Kusumawati. 2014. Dinamika Folikel Ovulasi setelah Sinkronisasi Estrus dengan Prostaglandin pada Sapi Perah. Jurnal Sains Veteriner 32(1), 22-30

Sariubang, M., Nurhayu. 2011. Respon Penyuntikan Hormon Capriglandin terhadap Sinkronisasi Berahi Induk Sapi Bali di Kabupaten Bantaenf Sulawesi selatan. Laporan Penelitian. Balai Pengkajian Teknologi Pertanian Sulawesi selatan.

Sonjaya. 2012. Dasar-Dasar Fisiologi Ternak. IPB Press. Bogor. 
Suhadji, 1995. Pengembangan bioteknologi peternakan. Keterkaitan penelitian pengkajian dan aplikasi. Prosiding Lokakarya Nasional I. Bioteknologi Peternakan Kerjasama antara Kantor Menristek dengan Departemen Pertanian. Pp. 45.

Sumaryadi, M.Y., W. Manalu, 1996. Hubungan antara jumlah folikel yang mengalami ovulasi terhadap keberhasilan kebuntingan domba pada berahi pertama setelah penyuntikan PGF2 $\alpha$. Media Veteriner III(1), 25-33.

Sumaryadi, M.Y., Haryati., W. Manalu. 2000. Efek Penyuntikan PMSG terhadap konsentrasi progesteron kaitannya dengan Pertumbuhan Kelenjar Uterus Domba pada Fase Luteal Siklus Berahi. Prosiding Seminar Nasional. Teknologi Peternakan dan Veteriner, Puslibangnak Bogor pp. 111-115.

Sumaryadi, M.Y. 2004. Pemanfaatan sumberdaya bioogis folikel untuk memperbaiki kinerja reproduksi induk resipien. Prosiding. Koordinasi dan Evaluasi Produksi, Transfer Embrio dan Progeny Test. Dirjen Bina Produksi Peternakan. Deptan. Jakarta. Pp. 109 113.

Susilawati, T. 2011. Tingkat keberhasilan inseminasi buatan dengan kualitas dan deposisi semen yang berbeda pada sapi Peranakan Ongole. Jurnal Ternak Tropika 12(2), 15-24.

Utomo B, R. Oelviani., Subiharta. 2015. Enhancing Perfomance of Weaned Ongole Calf Through Management Improvement Using Local Resources. Prosiding Seminar Nasional Masyarakat Biodiversity Indonesia 1(4), 838-842.

Walker, R. S., P. D. Burns, J. C. Whittier, G. E. Seidel., D. D. Zalesky. 2005. Evaluation of gonadotropin releasing hormone and insemination time using the $\mathrm{CO}$-synch protocol in beef cows. Prof. Anim. Sci. 21, 190.

Yusuf, M., Latief, A.T, Hasbi, Rauf, A. 2013. Pengaruh Perbedaan Metode Induksi Berahi Terhadap Lama Berahi Ternak Sapi Perah. Jurnal Penelitian. Fakultas Peternakan Universitas Hasanuddin, Makassar. 